\title{
ESI-FTICR Mass Spectrometric Study of Alcohol Complexation Properties of Mono- and Diphosphonate- Bridged Cavitands
}

\author{
Elina Ventola and Pirjo Vainiotalo \\ Department of Chemistry, University of Joensuu, Joensuu, Finland \\ Michele Suman and Enrico Dalcanale \\ Dipartimento di Chimica Organica e Industriale and INSTM, Università di Parma, Parma, Italy
}

\begin{abstract}
Alcohol complexation properties of eight mono- and diphenyl phosphonate-bridged cavitands (Scheme 1). were studied by electrospray ionization Fourier transform ion cyclotron resonance mass spectrometry (ESI-FTICR) and theoretical calculations. The cavitands varied in number and position of phenyl phosphonate bridges and their orientation with respect to the cavity, length of the lower rim alkyl chains, and substituents at apical positions of the resorcarene skeleton. The specificities of the different cavitands toward primary, secondary, and tertiary alcohols varying long of the alkyl chain were investigated, together with the stabilities of the formed complexes. The number, position, and orientation of the $\mathrm{P}=\mathrm{O}$ moieties affected the complex formation of the cavitands and stability of the complexes dramatically. Methyl groups at apical positions of the resorcarene skeleton also affected the complexation properties. Although length and branching of the alkyl chain of the alcohol influenced the complex formation, the effect on stability of the complexes was negligible. (J Am Soc Mass Spectrom 2006, 17, 213-221) (C) 2006 American Society for Mass Spectrometry
\end{abstract}

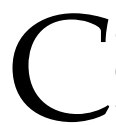
avitands are synthetic organic compounds with enforced cavities capable of molecular recognition [1-3]. Cavitands are particularly attractive as hosts because of the wide choice of suitable bridging groups, which shape the cavity and affect the properties of the cavitand. The most common bridging groups are alkylenedioxy [4], dialkylsilicon [5, 6], heterophenylene $[7,8]$, and phosphoryl $[9,10]$.

Cavitands form host-guest complexes with a variety of guest molecules and ions through their rigid, concave $\pi$-basic cavity, which enables electrostatic interactions such as cation- $\pi$ and $\mathrm{CH}-\pi$ interactions with the guests. In addition, appropriate substitution at the upper rim allows them to employ hydrogen bonding in the formation of complexes. Compared with resorcarenes, cavitands are extremely rigid molecules, which typically adopt a crown-like conformation both in solid-state and in solution, with only occasional minor deviations from this structure. Because of these features, cavitands functionalized with suitable substituents at the upper rim can form relatively stable complexes with guests appropriate for their preorganized structure.

Published online January 18, 2006

Address reprint requests to Professor P. Vainiotalo, Department of Chemistry, University of Joensuu, P.O. Box 111, Joensuu 80101, Finland. E-mail: pirjo.vainiotalo@joensuu.fi
Cavitands have been employed as sensitive layers in mass sensors [11]. They are easily coated on the surface of a mass sensitive sensor, where they form layers permeable to organic vapors after derivatization of the lower rim with long alkyl chains. Mass sensors coated with cavitands have been employed to detect volatile organic compounds such as aromatic hydrocarbons [12-15], alcohols [16, 17], and acetates [18].

Host-guest interactions of cavitands have traditionally been investigated by mass sensitive detection, X-ray diffraction methods and NMR spectroscopy. Mass spectrometry (MS) with a soft ionization technique such as electrospray ionization (ESI) [19-22] is nowadays challenging these more traditional methods in the study of host-guest interactions [23, 24]. As a technique, ESI-MS is positioned somewhere between the solution state and the gas phase. Results of titration and competition experiments have been found to correlate relatively well with the results of condensed phase techniques like NMR [25, 26]. In-source dissociation, collision induced dissociation (CID), and ion-molecule reactions, in contrast, describe the gas-phase properties of ions. Although gas-phase studies are valuable in understanding the interactions in supramolecular complexes without solvent influence, the results cannot be unambiguously transferred to solution phase. Some noncovalent interactions are strengthened in the absence of solvent, while others become less important. Not only the 


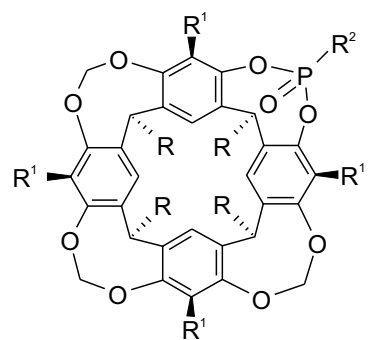

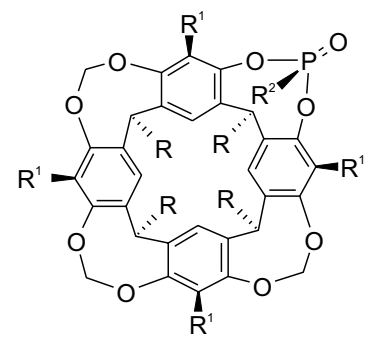

$\mathrm{Mi}\left[\mathrm{C}_{11} \mathrm{H}_{23}, \mathrm{H}, \mathrm{Ph}\right]$

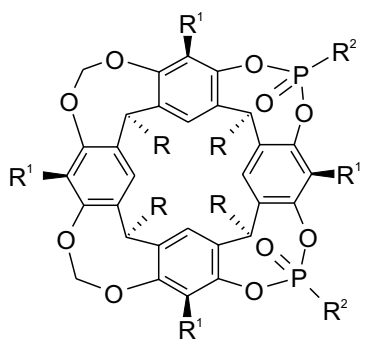

$$
A B i i\left[C_{11} H_{23}, H, P h\right]
$$

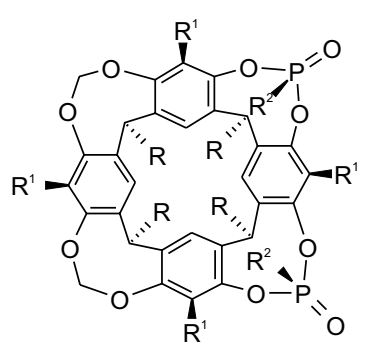
$A B o o\left[C_{11} H_{23}, H, P h\right]$

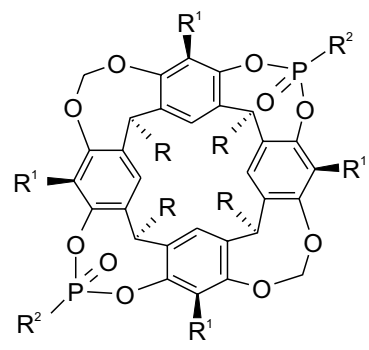

$\mathrm{ACii}\left[\mathrm{H}, \mathrm{CH}_{3}, \mathrm{Ph}\right]$

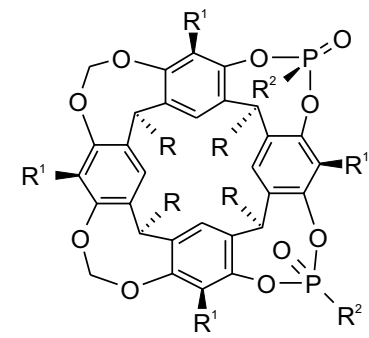

ABio[C $\left.\mathrm{C}_{11} \mathrm{H}_{23}, \mathrm{H}, \mathrm{Ph}\right]$

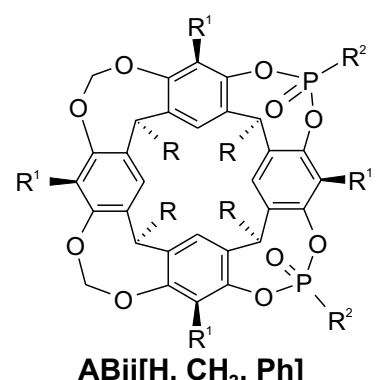

$\mathrm{ABii}\left[\mathrm{H}, \mathrm{CH}_{3}, \mathrm{Ph}\right]$

Scheme 1. Cavitands investigated. The nomenclature introduced in reference [11] is used: $M x, A B x x, A C x x\left[R, R^{1}, R^{2}\right]$.

lack of solvent but also the changes in vibrational modes of the host molecules in the gas phase affect the steric factors of the complex formation [27, 28].

During the past decade, mass spectrometric techniques [29-33] have been exploited to study the host-guest complexation properties of a variety of cavitand hosts. In the present work, electrospray ionization Fourier transform ion cyclotron resonance mass spectrometry (ESIFTICRMS) was used to investigate the ability of different mono- and diphenyl phosphonate-bridged cavitands (Scheme 1) to form host-guest complexes with a series of alcohols differing long of the alkyl chain and degree of substitution. The main interest was to elucidate the effects

on the formation and stability of complexes of number and relative position of $\mathrm{P}=\mathrm{O}$ groups and their orientation with respect to the cavity. The cavitands under study were expected to form hydrogen bonds with guest alcohols through their $\mathrm{P}=\mathrm{O}$ substituents. In addition, through the aromatic cavity they were expected to have $\mathrm{CH}-\pi$ interactions with the alkyl portion of the guests. Accordingly, another aim of the study was to evaluate the importance of synergistic $\mathrm{CH}-\pi$ and hydrogen bonding interactions in complex formation.

\section{Experimental}

\section{Equipment}

All mass spectrometry experiments were performed with the BioApex 47e Fourier transform ion cyclotron resonance mass spectrometer, equipped with an Infinity cell, a passively shielded 4.7 tesla $160-\mathrm{mm}$ bore superconducting magnet, and an external Apollo electrospray ionization source manufactured by Bruker Daltonics (Billerica, MA). The required $1 \cdot 10^{-9}$ torr vacuum was maintained by rotary vacuum pumps and turbomolecular pumps supplied by Edwards (Edwards High Vacuum International, Crawley, UK). The samples were introduced to a $70^{\circ}$ off-axis sprayer through a syringe infusion pump (Cole-Parmer 74900 series, ColeParmer Instrument Company, Vernon Hills, IL) at a flow rate of $90 \mu \mathrm{L} \mathrm{h}^{-1}$. Room-temperature nitrogen was used as nebulization and counter-current drying gas. Experimental parameters were kept as constant as possible to maintain comparable conditions. Ion-source voltages were mostly adjusted between $-3.8 \mathrm{kV}$ and $-4.0 \mathrm{kV}$ to end plate and between $-4.0 \mathrm{kV}$ and $-4.4 \mathrm{kV}$ to capillary. Capillary exit voltage was adjusted between $100 \mathrm{~V}$ and $350 \mathrm{~V}$. The measurements and data handling were accomplished with Bruker XMASS software version 6.0.2.

\section{Chemicals and Samples}

Previously introduced [11] nomenclature for the cavitands is used. The capital letters define the number and positions of the $\mathrm{P}=\mathrm{O}$ bridges, the lower case letters define the in-out stereochemistry at each phosphorous center, and $R, R^{1}$, and $R^{2}$ in brackets define the substituents at the lower rim, in the apical positions, and on the $\mathrm{P}(\mathrm{V})$ stereocenters, respectively (Scheme 1). Synthesis, characterization, and sensor performances have been reported for $\mathbf{M i}\left[\mathrm{C}_{\mathbf{1 1}} \mathbf{H}_{23}, \mathbf{H}, \mathbf{P h}\right], \mathbf{M o}\left[\mathrm{C}_{\mathbf{1 1}} \mathbf{H}_{23}, \mathbf{H}, \mathbf{P h}\right]$, $\mathrm{ABii}\left[\mathrm{C}_{11} \mathrm{H}_{23}, \mathrm{H}, \mathrm{Ph}\right], \quad \mathrm{ABio}\left[\mathrm{C}_{11} \mathbf{H}_{23}, \mathbf{H}, \mathbf{P h}\right]$, and $\mathbf{A B o o}\left[\mathbf{C}_{11} \mathbf{H}_{23}, \mathbf{H}, \mathbf{P h}\right][16,17]$. The preparation of $\mathrm{ABii}\left[\mathrm{H}, \mathrm{CH}_{3}, \mathrm{Ph}\right], \mathrm{ACii}\left[\mathrm{H}, \mathrm{CH}_{3}, \mathrm{Ph}\right]$, and $\mathrm{ACio}\left[\mathrm{H}, \mathrm{CH}_{3}\right.$, Ph] will be published elsewhere.

Samples for measurement contained $0.5-1.0 \%$ (vol/ vol) trifluoroacetic acid, 30-100\% (vol/vol) suitable alcohol and, correspondingly, $0-70 \%$ (vol/vol) acetonitrile $(\mathrm{ACN})$. Cavitand concentration in samples was 
Table 1. $m / z$ values and relative intensities of peaks observed in spectra measured from samples containing cavitand, ethanol, acetonitrile (ACN), and TFA

\begin{tabular}{|c|c|c|c|c|c|c|}
\hline Cavitand & $\begin{array}{c}{[\mathrm{M}+\mathrm{H}]^{+}} \\
m / z(\text { r.I. })\end{array}$ & $\begin{array}{c}{[\mathrm{M}+\mathrm{Na}]^{+}} \\
m / z(\text { r.l. })\end{array}$ & $\begin{array}{c}{[\mathrm{M}+\mathrm{K}]^{+}} \\
m / z \text { (r.I.) }\end{array}$ & $\begin{array}{c}{\left[\mathrm{M}+\mathrm{NH}_{4}\right]^{+}} \\
m / z \text { (r.I.) }\end{array}$ & ${ }^{[\mathrm{M}+\underset{\mathrm{EtOH}}{\mathrm{E} / z \text { (r.I.) }}}$ & ${ }^{[\mathrm{M}+\underset{m / z}{\mathrm{ACN}}(\text { r.l. })}$ \\
\hline $\mathrm{Mi}\left[\mathrm{C}_{11} \mathrm{H}_{23}, \mathrm{H}, \mathrm{Ph}\right]$ & $1264(0.23)$ & $1286(1.00)$ & $1302(0.36)$ & $* * *$ & $1309(0.93)$ & $* * *$ \\
\hline $\mathrm{ABii}\left[\mathrm{C}_{11} \mathrm{H}_{23}, \mathrm{H}, \mathrm{Ph}\right]$ & $1374(0.13)$ & $1396(0.59)$ & $1412(0.09)$ & $1391(0.44)$ & $1420(1.00)$ & $* * *$ \\
\hline $\mathrm{ACii}\left[\mathrm{H}, \mathrm{CH}_{3}, \mathrm{Ph}\right]$ & $813(0.04)$ & $835(0.75)$ & $851(0.10)$ & $830(0.18)$ & $859(1.00)$ & $* * *$ \\
\hline $\mathrm{ABii}\left[\mathrm{H}, \mathrm{CH}_{3}, \mathrm{Ph}\right]$ & $813(0.02)$ & $835(0.36)$ & $851(0.07)$ & $830(0.07)$ & $859(1.00)$ & $* * *$ \\
\hline $\mathrm{Mo}\left[\mathrm{C}_{11} \mathrm{H}_{23}, \mathrm{H}, \mathrm{Ph}\right]$ & $1264(1.00)$ & $1286(0.13)$ & $1302(0.07)$ & $* * *$ & $* * *$ & $1327(0.10)$ \\
\hline ABio $\left[\mathrm{C}_{11} \mathrm{H}_{23}, \mathrm{H}, \mathrm{Ph}\right]$ & $1374(1.00)$ & $1396(0.03)$ & $1412(0.07)$ & $* * *$ & $* * *$ & $1437(0.11)$ \\
\hline ABoo $\left[\mathrm{C}_{11} \mathrm{H}_{23}, \mathrm{H}, \mathrm{Ph}\right]$ & $1374(1.00)$ & $1396(0.22)$ & $1412(0.08)$ & $* * *$ & $* * *$ & $1437(0.09)$ \\
\hline $\mathrm{ACio}\left[\mathrm{H}, \mathrm{CH}_{3}, \mathrm{Ph}\right]$ & $813(1.00)$ & $835(0.03)$ & $851(0.05)$ & $* * *$ & $* * *$ & $876(0.13)$ \\
\hline
\end{tabular}

2.0-4.0 $\mu \mathrm{M}$. All reagents were commercially available and were used without further purification.

\section{Competition Experiments}

Competition experiments with cavitands were performed with a cavitand $\mathrm{d}_{1}$ cavitand $_{2}$ ratio of 1:1. Competition experiments with alcohols were performed against ethanol with an equimolar ethanol/alcohol ratio. The spectrum of each measurement consisted of 16 summed scans. Each experiment was carried out on five different samples and each sample was measured five times. The overall variance was calculated from the standard deviation of sampling and the standard deviation of the measurement $\left(s_{\text {tot }}^{2}=s_{1}^{2}+s_{2}^{2}\right)$. Samples or measurements were rejected if the average deviation of a suspect value from the mean was four or more times the average deviation of the retained values [34-36].

\section{Collision Induced Dissociation}

In collision induced dissociation (CID) experiments, collisionally cooled precursor ions were isolated by the $\mathrm{CHEF}$ procedure [37]. Isolated ions were thermalized during $3.0 \mathrm{~s}$ delay, translationally activated by an on-resonance radio frequency (RF) pulse, and allowed to collide with pulsed argon background gas. Each spectrum was a collection of 32 scans and all spectra were background corrected. $\mathrm{E}_{\mathrm{com}}$ values were calculated from experimental parameters using equations presented earlier [38-40]. Peak-to-peak voltage of the excitation RF pulse was measured directly from the output of the RF amplifier. The infinity cell was defined as having a diameter of $6 \mathrm{~cm}$ and geometrical factor of 0.897. Duration of the excitation pulse was $2 \mathrm{~ms}$.

Single collisions during the CID were pursued by tuning. However, the actual number of collisions and collision frequency has not been calculated. In this study, absolute dissociation constants were not aimed. The measurements were performed in identical conditions, and very similar systems (in terms of ionic radius, mass etc.) were compared to obtain information about the relative stability. Even though multiple collisions likely damp the kinetic energy of the ions and reduce the efficiency of collisions, we believe that in the case of relative stability data, the number of collisions is not likely to affect the results obtained.

\section{Theoretical Calculations}

Molecular mechanics calculations were made with $\mathrm{Ce}-$ rius2 4.8 software (Accelrys, San Diego, CA) using Universal 1.02 force field. Gaussian98 or Gaussian03 software [41-42] with Hartree-Fock method and 3-21G* basis set was used for ab initio structure optimizations and electrostatic potential (ESP) surface calculations starting from minimized structures obtained from molecular mechanics calculations. ESP surfaces were visualized using Molekel 4.3.win32 software (CSCS/ETHZ, Manno, Switzerland).

\section{Results and Discussion}

\section{Basic Spectra}

A basic requirement for mass spectrometric investigations is the existence of charge. Since both the host (cavitand) and the guest (alcohol) are neutral molecules, protonation was required for the measurements. Acetic acid was found to provide inadequate protonation, and trifluoroacetic acid (TFA) was used throughout the investigation, even though it impaired the signal to noise ratio $(\mathrm{S} / \mathrm{N})$ of the spectra. In earlier studies, related $\mathrm{P}(\mathrm{V})$ bridged cavitands were observed to possess noticeably higher proton affinities compared with those of alcohols. From that we reasonably assumed that protonation would occur expressly to $\mathrm{P}=\mathrm{O}$ oxygen of the cavitand, and that was indeed observed.

Basic spectra for all cavitands investigated were measured in 1:1 ethanol/ ACN solution containing 1.0\% TFA. All cavitands in which $\mathrm{P}=\mathrm{O}$ oxygens of the substituents were directed only toward the interior of the cavity easily formed an ethanol complex $[\mathbf{M}+$ $\mathrm{EtOH}+\mathrm{H}^{+}(\mathbf{M}=$ cavitand $)$. The observed $m / z$ values and relative intensities of the peaks are presented in Table 1.

In addition, variable amounts of adduct ions [M + $\mathrm{Na}]^{+},[\mathbf{M}+\mathrm{K}]^{+}$, and $\left[\mathbf{M}+\mathrm{NH}_{4}\right]^{+}$appeared in all spectra. These ions arise from nonavoidable impurities of the system, and their amount as well as the intensity 
a)

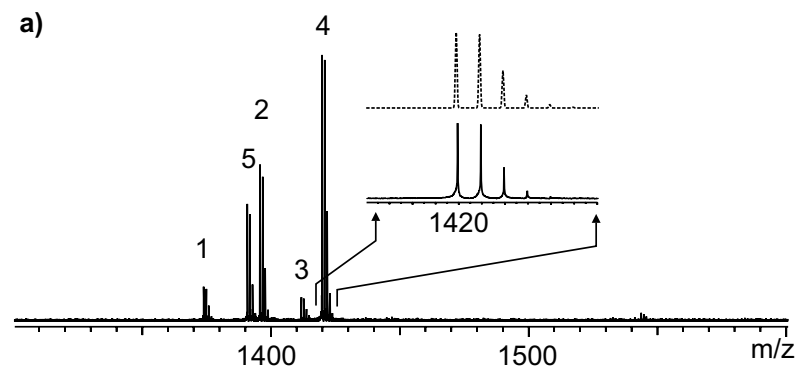

b)

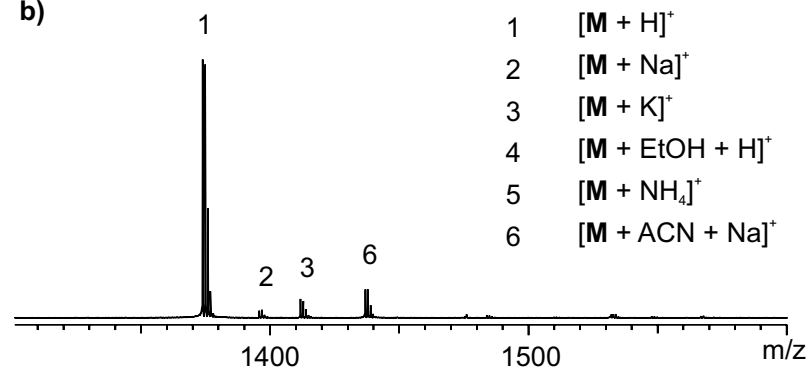

Figure 1. Basic spectra of cavitands (a) $\mathbf{A B i i}\left[\mathrm{C}_{11} \mathbf{H}_{23}, \mathbf{H}, \mathbf{P h}\right]$ and (b) $\mathrm{ABio}\left[\mathrm{C}_{\mathbf{1 1}} \mathrm{H}_{23}, \mathrm{H}, \mathrm{Ph}\right]$. Theoretical isotope pattern of the ethanol complex is shown with a dotted line and the experimental pattern with a solid line.

of the complexes varied with time. Formation of protonated cavitand was also clearly observed.

The composition of the alcohol complexes was confirmed by comparing the experimental monoisotopic $\mathrm{m} / \mathrm{z}$ values and isotopic patterns with the theoretical values calculated on the basis of natural abundances. The comparison for the ethanol complex of $\mathbf{A B i i}\left[\mathbf{C}_{11} \mathbf{H}_{23}, \mathbf{H}, \mathbf{P h}\right]$ is presented in Figure 1a (experimental pattern solid line and theoretical pattern dotted line). All ions were singly charged according to the isotopic distribution of the corresponding peaks. The mass differences between the experimental and theoretical values $(\Delta \mathrm{M})$ ranged from 0.050 to 0.125 . The match of the isotopic patterns was also sufficient, as the relative abundance of the second isotopic peak differed by only $0.5-5.0 \%$ from the theoretical value. All in all, the experimental values were in good agreement with the theoretical values, and the ions studied can truly be considered as noncovalent host-guest complexes.

With cavitands in which one or both $\mathrm{P}=\mathrm{O}$ groups were directed outward from the cavity, no ethanol complexes were formed (Table 1). Likewise, ammonium adduct ions were not formed. In spectra of $\mathbf{M o}\left[\mathrm{C}_{11} \mathrm{H}_{23}, \mathrm{H}, \mathbf{P h}\right], \mathbf{A B i o}\left[\mathrm{C}_{11} \mathrm{H}_{23}, \mathrm{H}, \mathbf{P h}\right]$ (Figure $1 \mathrm{~b}$ ), ABoo $\left[\mathrm{C}_{11} \mathrm{H}_{23}, \mathrm{H}, \mathrm{Ph}\right]$, and $\mathrm{ACio}\left[\mathrm{H}, \mathrm{CH}_{3}, \mathrm{Ph}\right]$, the most abundant peak was the one corresponding to protonated cavitand $[\mathbf{M}+\mathbf{H}]^{+}$. Instead of ethanol complex, some formation of the solvent adduct ion $[\mathbf{M}+\mathrm{ACN}+$ $\mathrm{Na}]^{+}$occurred. Most likely the formation of this adduct ion is a consequence of the strong affinity of acetonitrile for metal ions and it is not specific in nature. The formation of alkali metal adducts was poor with these cavitands in contrast to the cavitands in which $\mathrm{P}=\mathrm{O}$ groups are directed inwards.
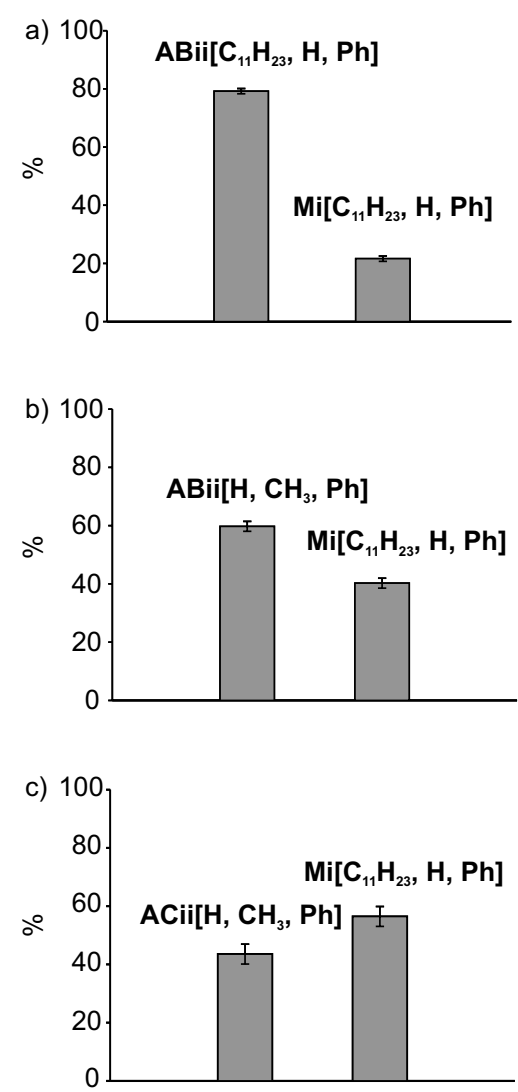

Figure 2. Mean intensities of ethanol complexes and overall variances obtained in competition experiments with (a) $\mathrm{ABii}\left[\mathrm{C}_{11} \mathrm{H}_{23}, \mathrm{H}, \mathrm{Ph}\right]$ and $\mathrm{Mi}\left[\mathrm{C}_{11} \mathrm{H}_{23}, \mathrm{H}, \mathrm{Ph}\right]$, (b) $\mathrm{ABii}\left[\mathrm{H}, \mathrm{CH}_{3}, \mathrm{Ph}\right]$ and $\mathbf{M i}\left[\mathbf{C}_{11} \mathbf{H}_{23}, \mathbf{H}, \mathbf{P h}\right]$, and (c) $\mathbf{A C i i}\left[\mathbf{H}, \mathbf{C H}_{3}, \mathbf{P h}\right]$ and $\mathbf{M i}\left[\mathbf{C}_{11} \mathbf{H}_{23}\right.$, $\mathbf{H}, \mathbf{P h}$. Percentages are presented relative to ethanol complexes. $(\%=([\mathrm{EtOH}+$ cavitand 1$] /[\mathrm{EtOH}+$ cavitand 1$]+[\mathrm{EtOH}+$ cavitand 2$])^{*} 100 \%$ )

\section{Competition Experiments}

Competition experiments with cavitands were performed to estimate preferences in their ethanol complex formation. All competition experiments were carried out in 1:1 ethanol/ACN solution, and only those cavitands for which complex formation ability had already been observed were investigated.

Mean intensities of ethanol complexes formed in competition experiments with $\left.\mathrm{ABii}_{\mathbf{1}} \mathbf{C}_{\mathbf{1 1}} \mathrm{H}_{\mathbf{2 3}}, \mathbf{H}, \mathbf{P h}\right]$ and $\mathbf{M i}\left[\mathbf{C}_{11} \mathbf{H}_{23}, \mathbf{H}, \mathbf{P h}\right]$ are presented in Figure 2a. According to the results, complex formation strongly depends on the number of $\mathrm{P}=\mathrm{O}$ groups directed towards the cavity, since the formation of ethanol complex of $\mathrm{ABii}\left[\mathrm{C}_{11} \mathrm{H}_{23}, \mathrm{H}, \mathrm{Ph}\right]$ is clearly preferred over that of ethanol complex of $\mathbf{M i}\left[\mathbf{C}_{11} \mathbf{H}_{23}, \mathbf{H}, \mathbf{P h}\right]$.

The effect of the relative position of the inwarddirected phenyl phosphonate substituents was investigated in competition experiments with $\mathbf{A B i i}\left[\mathbf{H}, \mathbf{C H}_{3}\right.$, $\mathrm{Ph}]$ and $\mathrm{ACii}\left[\mathrm{H}, \mathrm{CH}_{3}, \mathrm{Ph}\right]$ against $\mathrm{Mi}\left[\mathrm{C}_{\mathbf{1 1}} \mathrm{H}_{23}, \mathrm{H}, \mathrm{Ph}\right]$, the ethanol complexes of which give peaks in the same $\mathrm{m} / \mathrm{z}$ area. Results of these experiments are presented in Figure $2 \mathrm{~b}$ and $\mathrm{c}$. Note that, owing to the difference in mass of the competing cavitands, the experimental 
parameters were tuned to maximize the intensity of the ethanol complexes of $\mathbf{A B i i}\left[\mathbf{H}, \mathbf{C H}_{3}, \mathbf{P h}\right]$ and $\mathbf{A C i i}[\mathbf{H}$, $\mathrm{CH}_{3}, \mathrm{Ph}$ ] and were slightly different from the parameters otherwise used for the cavitands with $\mathrm{C}_{11} \mathrm{H}_{23}$ groups at the lower rim. The $\mathrm{AB}$ location of the phenyl phosphonate substituents on adjacent bridges seems to be more favorable than the AC location for ethanol complexation. The results also show that a methyl substituent in the apical position slightly reduces alcohol affinity, since the difference in complexation between $\mathrm{Mi}\left[\mathrm{C}_{11} \mathrm{H}_{23}, \mathrm{H}, \mathrm{Ph}\right]$ and $\mathrm{ABii}\left[\mathrm{H}, \mathrm{CH}_{3}, \mathrm{Ph}\right]$ (Figure $2 \mathrm{~b}$ ) is not as great as the difference in complexation between $\mathrm{Mi}\left[\mathrm{C}_{11} \mathrm{H}_{23}, \mathrm{H}, \mathrm{Ph}\right]$ and $\mathrm{ABii}\left[\mathrm{C}_{11} \mathrm{H}_{23}, \mathrm{H}, \mathrm{Ph}\right]$ (Figure 2a). ACii[H, $\left.\mathbf{C H}_{3}, \mathbf{P h}\right]$ would be expected to form ethanol complex with at least the same efficiency as $\mathbf{M i}\left[\mathbf{C}_{11} \mathbf{H}_{23}, \mathbf{H}, \mathbf{P h}\right]$, especially since the experimental parameters were designed to favor the detection of $\mathrm{ACii}\left[\mathrm{H}, \mathbf{C H}_{3}, \mathbf{P h}\right]$ complex, but this was not the case.

In earlier studies on similar cavitands, the relative configuration [43] and number of $\mathrm{P}=\mathrm{O}$ groups have been found strongly to affect the efficiency of complex formation. In the case of alkyl ammonium ion guests, the presence of two or more inward-directed $\mathrm{P}=\mathrm{O}$ groups allowed the formation of several hydrogen bonds with the guests and increased the abundance of complexes [32]. Similarly, in a study where neutral amines were used as guests, multiple inward orientation of $\mathrm{P}=\mathrm{O}$ groups increased the complex formation of protonated cavitands [31]. In this last case, however, gas-phase ion-molecule reactions in the ESI-FTICR mass spectrometer did not support the formation of multiple hydrogen bonds between the cavitand host and amine guests.

It must be emphasized that where the complexation study by mass spectrometry is carried out with ionic guests, such as alkyl ammonium ions, the $\mathrm{P}=\mathrm{O}$ groups of the cavitand are able to function solely as hydrogen bond acceptors. In MS studies with neutral guests, on the other hand, the charge necessary for observation of the complexes is typically brought by protonation. If the protonation occurs to $\mathrm{P}=\mathrm{O}$ groups of the cavitand, this dramatically alters the hydrogen bond acceptor character of the cavitand, because at least one of the $\mathrm{P}=\mathrm{O}$ groups then functions more as a hydrogen bond donor than as an acceptor. Certainly, in MS experiments with neutral guests, the formation of multiple hydrogen bonds in which $\mathrm{P}=\mathrm{O}$ groups function solely as hydrogen bond acceptor is impossible. But two or more inward-directed $\mathrm{P}=\mathrm{O}$ groups might achieve forms of cooperative binding if multicentered hydrogen bonds were possible. One of the $\mathrm{P}=\mathrm{O}$ groups would then serve as hydrogen bond donor through the attached proton, while one or more of the other groups serve as an acceptor of hydrogen bond.

To study the effect of the guest, we carried out competition experiments with secondary and tertiary alcohols, as well as with primary alcohols with different length of alkyl chain. Cavitands $\mathrm{Mi}\left[\mathrm{C}_{\mathbf{1 1}} \mathbf{H}_{\mathbf{2 3}}, \mathbf{H}, \mathbf{P h}\right]$, $\mathrm{ABii}\left[\mathrm{C}_{11} \mathrm{H}_{23}, \mathrm{H}, \mathrm{Ph}\right], \mathrm{ABii}\left[\mathrm{H}, \mathrm{CH}_{3}, \mathrm{Ph}\right]$, and $\mathrm{ACii}[\mathrm{H}$,

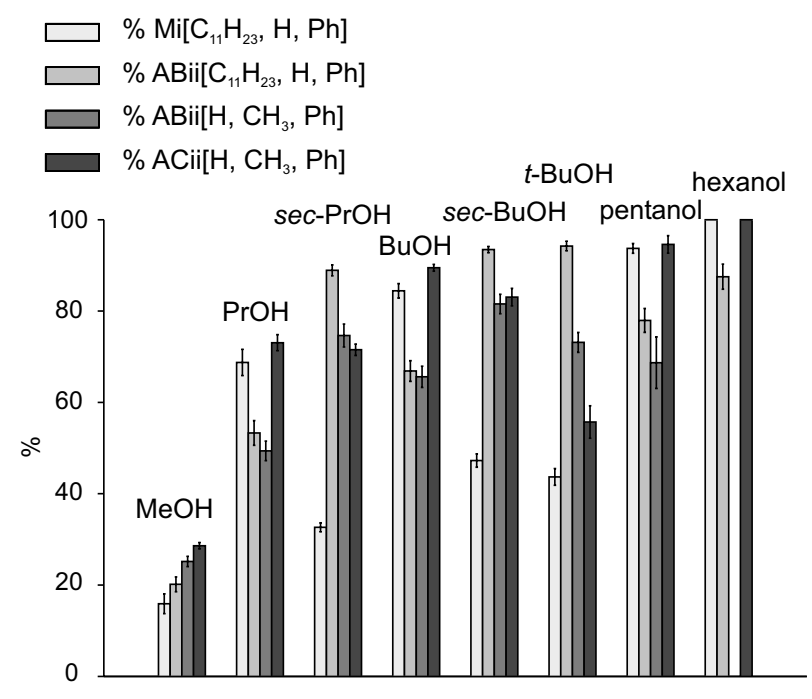

Figure 3. Competition of alcohols in the presence of $\mathbf{M i}\left[\mathrm{C}_{11} \mathbf{H}_{23}\right.$, $\mathrm{H}, \mathrm{Ph}], \mathrm{ABii}\left[\mathrm{C}_{11} \mathrm{H}_{23}, \mathrm{H}, \mathrm{Ph}\right], \mathrm{ABii}\left[\mathrm{H}, \mathrm{CH}_{3}, \mathrm{Ph}\right]$, and $\mathrm{ACii}\left[\mathrm{H}, \mathrm{CH}_{3}\right.$, $\mathrm{Ph}$. Percentages are presented relative to ethanol complexes. $(\%=$ ([alcohol $\cdot$ cavitand] / [alcohol $\cdot$ cavitand] + [ethanol $\cdot$ cavitand]) $* 100 \%)$

$\mathrm{CH}_{3}, \mathbf{P h}$ ] were chosen for the experiments, and ethanol was used as the standard to which complexation efficiency was compared. The measured solutions contained equimolar amounts of ethanol and competing alcohol and $350-683 \mu \mathrm{L}$ of acetonitrile to improve the electrospray conditions. Even with the ACN, the electrospray conditions sometimes became so unstable with the longer linear alcohols that measurements had to be abandoned. Results of the experiments investigating the competition of alcohols for the cavitands are presented in Figure 3.

As can be seen in Figure 3, $\mathbf{M i}\left[\mathbf{C}_{\mathbf{1 1}} \mathbf{H}_{\mathbf{2 3}}, \mathbf{H}, \mathbf{P h}\right]$ and $\mathrm{ACii}\left[\mathrm{H}, \mathbf{C H}_{3}, \mathbf{P h}\right]$ generally prefer primary alcohols in complex formation. Moreover, relative abundance of the peaks corresponding to primary alcohol complexes increases with length of the alkyl chain. The complex formation efficiency with $\mathrm{Mi}\left[\mathrm{C}_{11} \mathrm{H}_{23}, \mathrm{H}, \mathrm{Ph}\right]$ and ACii $\left[\mathbf{H}, \mathbf{C H}_{3}, \mathbf{P h}\right]$ was clearly lower for secondary and tertiary alcohols than for primary alcohols.

With ABii cavitands, as with $\mathbf{M i}\left[\mathbf{C}_{11} \mathbf{H}_{23}, \mathbf{H}, \mathbf{P h}\right]$ and $\mathrm{ACii}\left[\mathrm{H}, \mathbf{C H}_{3}, \mathbf{P h}\right]$, the relative abundance of the peaks corresponding to primary alcohol complexes increases with length of the alkyl chain. However, the complex formation efficiency with the ABii cavitands appeared to be higher for the secondary and tertiary alcohols than the primary alcohols.

Three possible explanations can be suggested for the more abundant complex formation of longer than of shorter chain primary alcohols with $\mathbf{M i}\left[\mathbf{C}_{\mathbf{1 1}} \mathbf{H}_{\mathbf{2 3}}, \mathbf{H}, \mathbf{P h}\right]$, $\mathrm{ABii}\left[\mathrm{C}_{11} \mathrm{H}_{23}, \mathrm{H}, \mathrm{Ph}\right], \mathrm{ABii}\left[\mathrm{H}, \mathrm{CH}_{3}, \mathrm{Ph}\right]$, and $\mathrm{ACii}[\mathrm{H}$, $\left.\mathrm{CH}_{3}, \mathrm{Ph}\right]$.

(1) Since the proton affinity of the alcohol increases with the chain length, the hydrogen bond between the alcohol and the protonated cavitand would correspondingly increase in strength, and the complex formed 


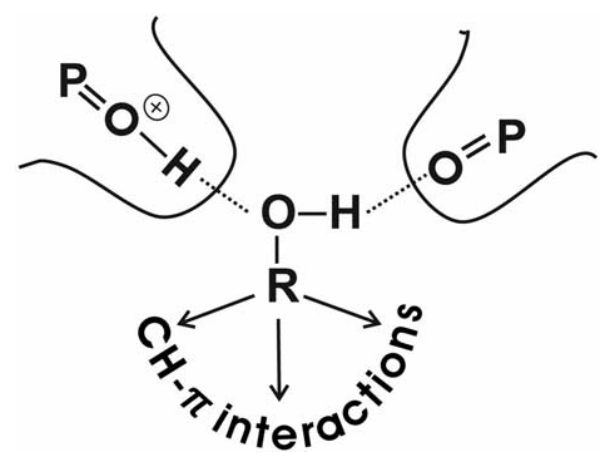

Figure 4. Schematic presentation of proposed noncovalent interactions between alcohol and two phosphonate substituents.

would be thermodynamically more stable. This argument would not, however, explain the more abundant complexation of primary alcohols with $\mathbf{M i}\left[\mathrm{C}_{\mathbf{1 1}} \mathbf{H}_{\mathbf{2 3}}, \mathrm{H}\right.$, $\mathbf{P h}]$, and $\mathrm{ACii}\left[\mathrm{H}, \mathrm{CH}_{3}, \mathbf{P h}\right]$ compared with secondary and tertiary alcohols, because the proton affinities of primary, secondary, and tertiary alcohols are of similar magnitude. In fact, according to Kamlet-Taft $\beta$ parameters, the ability of secondary and tertiary alcohols to act as hydrogen bond acceptor is greater than that of primary alcohols [44, 45]. Interestingly, studies performed on primary alcohols with mass sensitive sensors have shown the same trend in complexation as our study $[16,17]$. In the case of sensors, this is attributable to the increase of unspecific dispersion interaction between the alkyl chains at the lower rim of the cavitands and the alkyl chains of the alcohol. In our study, the increase in complex formation efficiency with chain length is not, however, dependent on the lower rim alkyl chains of the cavitand because $\mathrm{ABii}\left[\mathrm{C}_{11} \mathrm{H}_{23}, \mathrm{H}, \mathrm{Ph}\right]$ and $\mathrm{ABii}[\mathrm{H}$, $\mathrm{CH}_{3}, \mathbf{P h}$ ] behaved similarly with longer primary alcohols. In mass spectrometric experiments with protonated cavitands, the protonated $\mathrm{P}=\mathrm{O}$ group serves more as a hydrogen bond donor than as an acceptor, and it is more likely that the complexation efficiency would increase with the proton affinity of the alcohol.

(2) Compared with shorter chain alcohols, longer chain alcohols can be considered less solvated because of their hydrophobic alkyl chains, and the lower degree of solvation may contribute to the enhanced complex formation. Additionally, reduced solvation may increase the ionization efficiency of complexes and facilitate the observation of the complexes after the ESI process.

(3) The probability of having stabilizing $\mathrm{CH}-\pi$ interactions increases with chain length of the alcohol.

According to our findings, with cavitands ABii $\left[\mathrm{C}_{11} \mathrm{H}_{23}, \mathrm{H}, \mathrm{Ph}\right]$ and $\mathrm{ABii}\left[\mathrm{H}, \mathrm{CH}_{3}, \mathrm{Ph}\right]$, alcohols probably form a hydrogen bond network with adjacent $\mathrm{P}=\mathrm{O}$ oxygens, so that the cavitand serves as both hydrogen bond donor and as hydrogen bond acceptor (Figure 4). In complexes with ABii cavitands, the oxygen of the alcohol lies between the $\mathrm{P}=\mathrm{O}$ oxygens of the cavitand and acts as hydrogen bond acceptor with protonated $\mathrm{P}=\mathrm{O}$ group and hydrogen bond donor with unprotonated $\mathrm{P}=\mathrm{O}$ group. In this kind of orientation, alkyl chains of secondary and tertiary alcohols would better stabilize the structure of the complex than those of primary alcohols through multiple favorable $\mathrm{CH}-\pi$ interactions with the aromatic rings of the cavity.

A similar position of the alcohol in cavitand $\mathrm{Mi}\left[\mathrm{C}_{11} \mathbf{H}_{23}, \mathbf{H}, \mathbf{P h}\right]$ is not possible because of repulsion between $\mathrm{OH}$ of the alcohol and the $\mathrm{CH}_{2}$ bridge of the cavitand. Decreased complex formation of $\mathbf{M i}\left[\mathbf{C}_{11} \mathbf{H}_{23}\right.$, $\mathbf{H}, \mathbf{P h}]$ and $\mathrm{ACii}\left[\mathrm{H}, \mathrm{CH}_{3}, \mathrm{Ph}\right]$ with secondary and tertiary alcohols relative to primary alcohols is probably caused by nonstabilizing orientation of the alkyl chains of secondary and tertiary alcohols. Moreover, in this orientation, favorable $\mathrm{CH}-\pi$ interaction between alkyl chain of longer primary alcohols and the aromatic ring of the substituent may be possible. In addition, $\mathrm{Mi}\left[\mathrm{C}_{11} \mathrm{H}_{23}, \mathrm{H}, \mathrm{Ph}\right]$ does not support the same kind of hydrogen bond system as ABii cavitands and, as a consequence, overall affinity towards alcohols is decreased. In cavitand $\mathbf{A C i i}\left[\mathbf{H}, \mathbf{C H}_{3}, \mathbf{P h}\right]$, because of the anti position of the two $\mathrm{P}=\mathrm{O}$ groups, the available space in the cavity is reduced, and the sterically more demanding secondary and tertiary alcohols are not favored over the corresponding primary ones.

\section{Collision Induced Dissociation}

Differences in gas-phase stability of the alcohol complexes were studied by CID measurements. Single-frequency excitation shots were observed to bring a variable amount of additional energy to complexes, and their use was therefore avoided and monoisotopic isolations were not pursued. CID experiments were performed with ethanol complexes of $\mathrm{Mi}\left[\mathrm{C}_{11} \mathrm{H}_{23}, \mathrm{H}, \mathrm{Ph}\right], \mathrm{ABii}\left[\mathrm{H}, \mathrm{CH}_{3}, \mathrm{Ph}\right]$, and ACii $\left[\mathbf{H}, \mathbf{C H}_{3}, \mathbf{P h}\right]$ and with methanol, ethanol, propanol, sec-propanol, butanol, sec-butanol, and $t$-butanol complexes of $A B i i\left[C_{11} \mathbf{H}_{23}, \mathbf{H}, \mathbf{P h}\right]$.

Ethanol complexes of all cavitands dissociated producing protonated cavitand $\left[\mathbf{M}+\mathrm{H}^{+}\right.$as a product ion. No protonated alcohols or other product ions were observed, confirming our earlier assumption that proton affinities of cavitands are greater than proton affinities of alcohols. A comparison of the dissociation of the ethanol complexes of cavitands $\mathbf{M i}\left[\mathrm{C}_{\mathbf{1 1}} \mathbf{H}_{\mathbf{2 3}}, \mathbf{H}, \mathbf{P h}\right]$, $\mathrm{ABii}\left[\mathrm{C}_{11} \mathrm{H}_{23}, \mathrm{H}, \mathrm{Ph}\right], \mathrm{ABii}\left[\mathrm{H}, \mathrm{CH}_{3}, \mathbf{P h}\right]$, and $\mathrm{ACii}[\mathrm{H}$, $\left.\mathbf{C H}_{3}, \mathbf{P h}\right]$ is presented in Figure 5. Clear differences in stability were evident between these complexes: the ethanol complex of $\mathbf{A B i i}\left[\mathbf{C}_{\mathbf{1 1}} \mathbf{H}_{\mathbf{2 3}}, \mathbf{H}, \mathbf{P h}\right]$ required noticeably higher energy for dissociation than did the ethanol complex of $\mathbf{M i}\left[\mathbf{C}_{\mathbf{1 1}} \mathbf{H}_{23}, \mathbf{H}, \mathbf{P h}\right]$, and the ethanol complex of $\mathbf{A B i i}\left[\mathbf{H}, \mathbf{C H}_{3}, \mathbf{P h}\right]$ was kinetically more stable than the ethanol complex of $\mathbf{A C i i}\left[\mathbf{H}, \mathbf{C H}_{3}, \mathbf{P h}\right]$. These findings confirm the importance of the number and position of the $\mathrm{P}=\mathrm{O}$ groups to the stability of the complexes. Comparison of cavitands $\mathrm{ABii}\left[\mathbf{C}_{\mathbf{1 1}} \mathbf{H}_{\mathbf{2 3}}, \mathbf{H}\right.$, $\mathrm{Ph}]$ and $\mathrm{ABii}\left[\mathrm{H}, \mathrm{CH}_{3}, \mathrm{Ph}\right]$ and cavitands $\mathrm{Mi}\left[\mathrm{C}_{11} \mathrm{H}_{23}, \mathrm{H}\right.$, $\mathbf{P h}]$ and $\mathrm{ACii}\left[\mathrm{H}, \mathrm{CH}_{3}, \mathbf{P h}\right.$ ] shows that the methyl substituents at apical positions of $\mathrm{ABii}\left[\mathrm{H}, \mathbf{C H}_{3}, \mathbf{P h}\right]$ and 


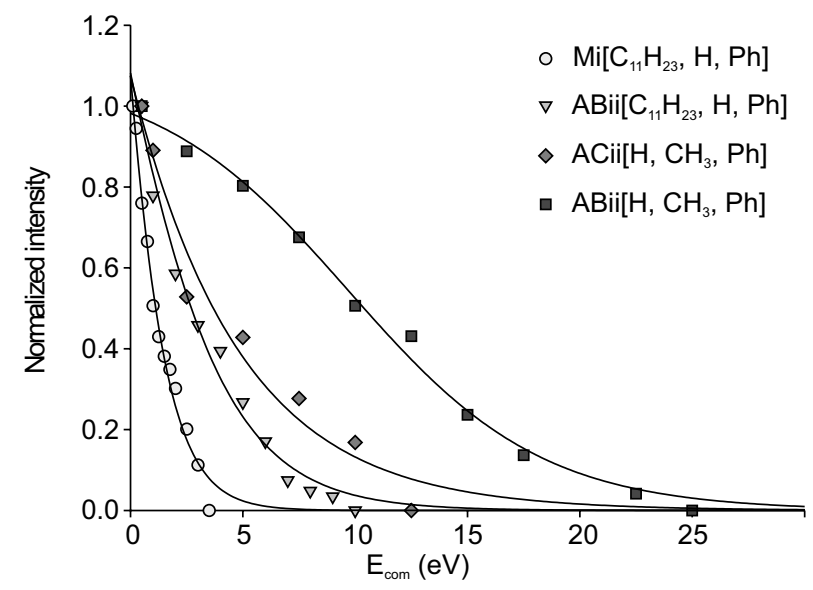

Figure 5. Dissociation of the ethanol complexes of cavitands $\mathrm{Mi}\left[\mathrm{C}_{11} \mathrm{H}_{23}, \mathrm{H}, \mathrm{Ph}\right]$ and $\mathrm{ABii}\left[\mathrm{C}_{11} \mathrm{H}_{23}, \mathrm{H}, \mathrm{Ph}\right], \mathrm{ACii}\left[\mathrm{H}, \mathrm{CH}_{3}, \mathrm{Ph}\right]$ and $\mathrm{ABii}\left[\mathbf{H}, \mathbf{C H}_{3}, \mathbf{P h}\right]$. Normalized intensities as a function of activation energy $(\mathrm{eV})$.

ACii $\left[\mathbf{H}, \mathrm{CH}_{3}, \mathbf{P h}\right]$ increase the kinetic stability of the ethanol complexes.

The stability of the complexes formed with different alcohols was investigated in CID experiments carried out with $\mathrm{ABii}\left[\mathrm{C}_{\mathbf{1 1}} \mathbf{H}_{23}, \mathbf{H}, \mathbf{P h}\right]$ and methanol, propanol, secpropanol, butanol, sec-butanol, and $t$-butanol. Dissociation curves of the complexes did not reveal any marked differences in their kinetic stability. Sigmoidal fitting of the curves was utilized and $\mathrm{E}_{\mathrm{com}}^{0.5}$ values, which represent the activation energy where half of the isolated complex has dissociated, were calculated (Table 2).

Although longer alkyl chain was clearly associated with increased complex formation, as reported above, it did not seem to affect the gas-phase stability of the complexes. The differences in stability of the complexes formed with different alcohols were minor and there was no consistent trend in the stabilities.

\section{Theoretical Calculations}

Theoretical methods were used in conjunction with mass spectrometry to confirm that the observed complexation behavior was attributable to the configurational properties

Table 2. $\mathrm{E}_{\mathrm{com}}^{0.5}$ values of dissociation for cavitand-alcohol complexes

\begin{tabular}{llrl}
\hline \multicolumn{1}{c}{ Cavitand } & Alcohol & $\mathrm{E}_{\text {com }}^{0.5}$ & $\mathrm{R}^{\mathrm{ab}}$ \\
\hline \hline $\mathrm{Mi}\left[\mathrm{C}_{11} \mathrm{H}_{23}, \mathrm{H}, \mathrm{Ph}\right]$ & $\mathrm{EtOH}$ & 1.12 & 0.9877 \\
$\mathrm{ABii}\left[\mathrm{C}_{11} \mathrm{H}_{23}, \mathrm{H}, \mathrm{Ph}\right]$ & $\mathrm{EtOH}$ & 2.71 & 0.9850 \\
$\mathrm{ACii}\left[\mathrm{H}, \mathrm{CH}_{3}, \mathrm{Ph}\right]$ & $\mathrm{EtOH}$ & 3.69 & 0.9676 \\
$\mathrm{ABii}\left[\mathrm{H}, \mathrm{CH}_{3}, \mathrm{Ph}\right]$ & $\mathrm{EtOH}$ & 10.40 & 0.9943 \\
$\mathrm{ABii}\left[\mathrm{C}_{11} \mathrm{H}_{23}, \mathrm{H}, \mathrm{Ph}\right]$ & $\mathrm{MeOH}$ & 3.26 & 0.9887 \\
$\mathrm{ABii}\left[\mathrm{C}_{11} \mathrm{H}_{23}, \mathrm{H}, \mathrm{Ph}\right]$ & $\mathrm{PrOH}$ & 3.64 & 0.9965 \\
$\mathrm{ABii}\left[\mathrm{C}_{11} \mathrm{H}_{23}, \mathrm{H}, \mathrm{Ph}\right]$ & sec-PrOH & 3.40 & 0.9975 \\
$\mathrm{ABii}\left[\mathrm{C}_{11} \mathrm{H}_{23}, \mathrm{H}, \mathrm{Ph}\right]$ & $\mathrm{BuOH}$ & 2.78 & 0.9775 \\
$\mathrm{ABii}\left[\mathrm{C}_{11} \mathrm{H}_{23}, \mathrm{H}, \mathrm{Ph}\right]$ & sec-BuOH & 3.49 & 0.9965 \\
$\mathrm{ABii}\left[\mathrm{C}_{11} \mathrm{H}_{23}, \mathrm{H}, \mathrm{Ph}\right]$ & $t$-BuOH & 3.70 & 0.9984
\end{tabular}

${ }^{a}$ Activation energy where half of the complex is dissociated $(\mathrm{eV})$ bCorrelation of sigmoidal fit.
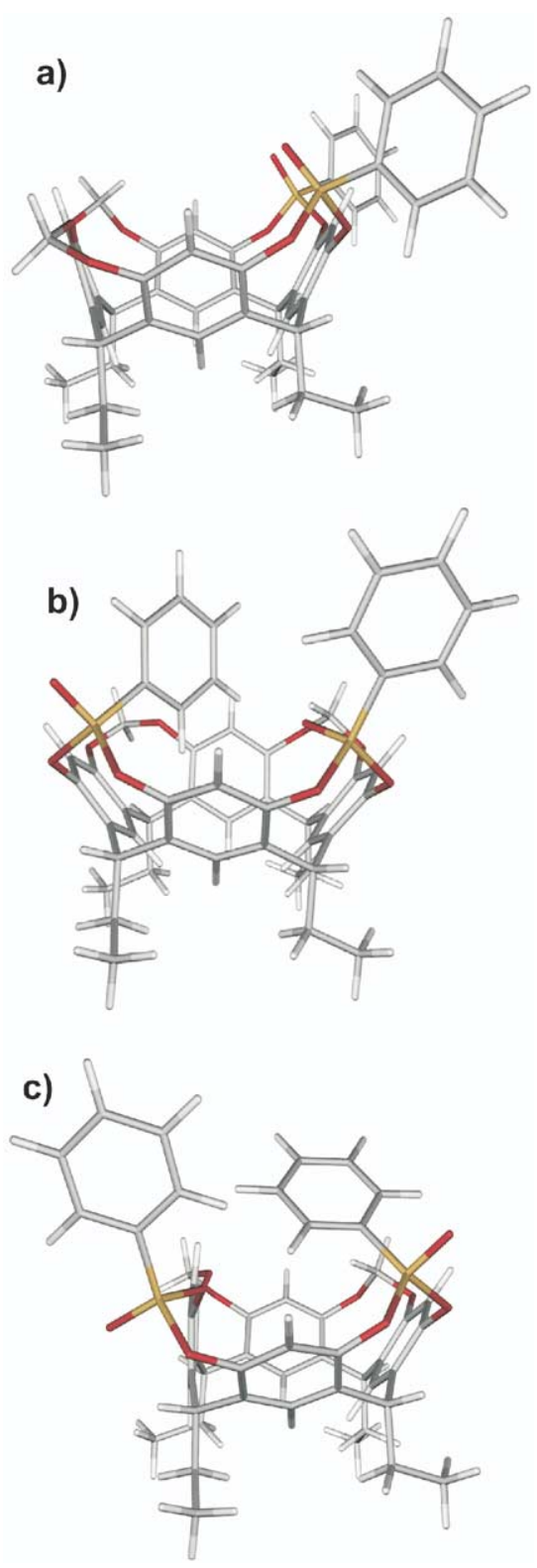

Figure 6. Cavitand structures obtained from ab initio optimizations (basis set 3-21G*): (a) ABii[ $\left.\mathbf{C}_{2} \mathbf{H}_{5}, \mathbf{H}, \mathbf{P h}\right],\left(\right.$ b) $\mathbf{A B i o}\left[\mathbf{C}_{2} \mathbf{H}_{5}, \mathbf{H}\right.$, $\mathrm{Ph}]$, and (c) $\mathrm{ABoo}\left[\mathrm{C}_{2} \mathrm{H}_{5}, \mathrm{H}, \mathrm{Ph}\right]$.

of the cavitands. All the cavitands were built and roughly optimized by molecular mechanics method, and the structures were then further optimized by ab initio HartreeFock method. Owing to resource requirements, $\mathrm{C}_{11} \mathrm{H}_{23}$ alkyl chains were replaced by ethyl chains, but this was not expected to alter the results for the cavity and upper rim.

In the cavitand $\mathrm{Mo}\left[\mathrm{C}_{2} \mathrm{H}_{5}, \mathrm{H}, \mathrm{Ph}\right]$, the phenyl ring of the phosphonate bridging group fills the cavity, effectively blocking it. In diphosphonate-bridged cavitands, a single phenyl ring directed above the cavity is sufficient to block the cavity and prevent the complexation process, even when the $\mathrm{P}=\mathrm{O}$ substituent of the adjacent bridging group is orientated appropriately inwards for complexation. This orientation can be seen in Figure 6, where the 

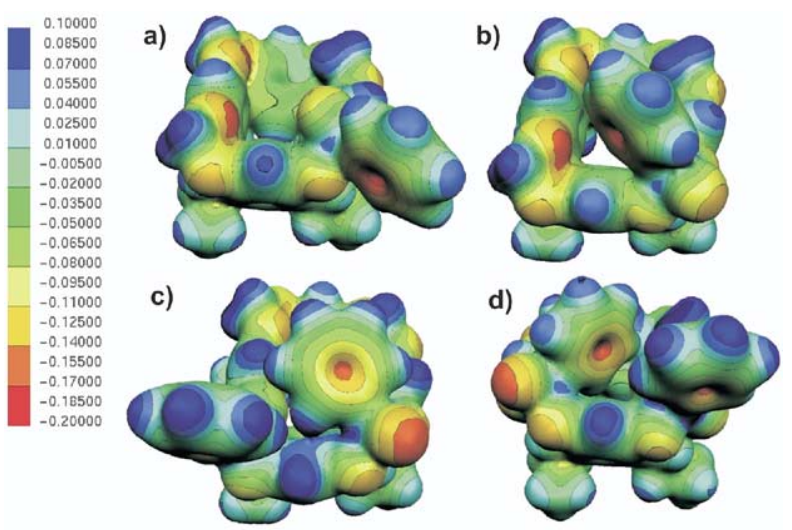

e)

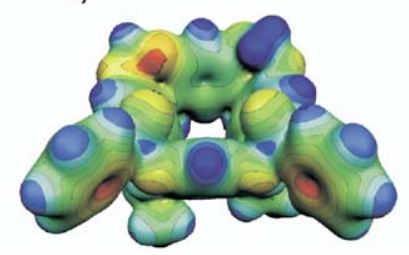

Figure 7. ESP surfaces of cavitands (a) $\mathrm{Mi}\left[\mathrm{C}_{2} \mathrm{H}_{5}, \mathrm{H}, \mathrm{Ph}\right]$, (b) $\mathrm{Mo}\left[\mathrm{C}_{2} \mathrm{H}_{5}, \mathrm{H}, \mathrm{Ph}\right]$, (c) ABio[ $\left[\mathrm{C}_{2} \mathrm{H}_{5}, \mathrm{H}, \mathrm{Ph}\right]$, (d) $\mathrm{ABoo}\left[\mathrm{C}_{2} \mathrm{H}_{5}, \mathrm{H}, \mathrm{Ph}\right]$, and (e) $\mathbf{A B i i}\left[\mathbf{C}_{2} \mathbf{H}_{5}, \mathbf{H}, \mathbf{P h}\right]$. Charges range from 0.1 (blue) to -0.2 (red).

ab initio optimized conformations of $\mathbf{A B i i}\left[\mathrm{C}_{2} \mathbf{H}_{5}, \mathbf{H}, \mathbf{P h}\right]$, $\mathrm{ABio}\left[\mathrm{C}_{2} \mathrm{H}_{5}, \mathrm{H}, \mathrm{Ph}\right]$, and $\mathrm{ABoo}\left[\mathrm{C}_{2} \mathrm{H}_{5}, \mathrm{H}, \mathrm{Ph}\right]$ are presented. $\mathrm{ABoo}\left[\mathrm{C}_{2} \mathrm{H}_{5}, \mathbf{H}, \mathbf{P h}\right]$ does not have enough space for both phenyl rings to lie above the cavity and one of the rings remains upright. The number of inward facing $\mathrm{P}=\mathrm{O}$ groups does not appear to have a noticeable influence on the size or dimensions of the cavity of the cavitands. Energetically, the most favorable configuration of the di-bridged cavitands appears to be $\mathrm{ABii}\left[\mathrm{C}_{2} \mathbf{H}_{5}, \mathbf{H}, \mathbf{P h}\right]$; the differences are small, however. Synthetically, it is the preferred one only in the presence of a template [11].

Charge distributions were determined for optimized structures of $\mathrm{Mi}\left[\mathrm{C}_{2} \mathrm{H}_{5}, \mathrm{H}, \mathrm{Ph}\right], \mathrm{Mo}\left[\mathrm{C}_{2} \mathrm{H}_{5}, \mathrm{H}, \mathrm{Ph}\right]$, $\mathrm{ABii}\left[\mathrm{C}_{2} \mathrm{H}_{5}, \mathrm{H}, \mathrm{Ph}\right], \mathrm{ABio}\left[\mathrm{C}_{2} \mathrm{H}_{5}, \mathrm{H}, \mathrm{Ph}\right]$, and $\mathrm{ABoo}\left[\mathrm{C}_{2} \mathrm{H}_{5}\right.$, $\mathbf{H}, \mathbf{P h}]$ to confirm that the gas-phase structures of the cavitands do not differ markedly in charge distribution, which alone could induce differences in complexation. The charge distributions of the cavitands as electrostatic potential surfaces (ESP surfaces) are presented in Figure 7. As expected, negative charge is concentrated on the oxygen atoms and phenyl rings and the $\mathrm{P}=\mathrm{O}$ oxygen has slightly more electron density when it is directed outward from the cavity. Likewise, bridge oxygens situated closer to the center of the cavity carry more electron density. All in all, the differences in the charge distributions of the configurations are too slight to explain the divergent abilities of the cavitands to form noncovalent alcohol complexes. From the ESP surfaces, however, it can be concluded that the protonation of the cavitands expressly occurs to the $\mathrm{P}=\mathrm{O}$ oxygen of the bridging group, as assumed earlier.

\section{Conclusions}

ESI FT-ICR mass spectrometric study showed the number and position of the $\mathrm{P}=\mathrm{O}$ groups and their orientation with respect to the cavity to be the main determinants of the complexation efficiency of cavitands towards alcohols.

The cavitands in which $\mathrm{P}=\mathrm{O}$ oxygen(s) were directed only inwards formed alcohol complexes easily. Theoretical calculations showed that when a $\mathrm{P}=\mathrm{O}$ oxygen is directed outward, the phenyl ring of the phosphonate bridging group fills the cavity, effectively blocking it. Even with one inward-directed $\mathrm{P}=\mathrm{O}$ group, as in cavitands $\mathbf{A B i o}\left[\mathbf{C}_{\mathbf{1 1}} \mathbf{H}_{23}, \mathbf{H}, \mathbf{P h}\right]$ and ACio $\left[\mathbf{H}, \mathbf{C H}_{3}, \mathbf{P h}\right]$, complexation of ethanol within the cavity is blocked by the phenyl ring of the outwarddirected phenyl phosphonate substituent and no complexation is observed. The results suggest that the cavity of the cavitand plays a major role in the complex formation. This was especially evident for the monophosphonate-bridged cavitands. If hydrogen bonding were the only important factor in complexation, the cavitands $\mathrm{Mo}\left[\mathrm{C}_{11} \mathrm{H}_{23}, \mathrm{H}, \mathrm{Ph}\right]$ and $\mathrm{Mi}\left[\mathrm{C}_{11} \mathrm{H}_{23}, \mathrm{H}, \mathrm{Ph}\right]$ would be expected to form ethanol complexes with the same efficiency, and this was not the case. The results strongly imply that the $\mathrm{CH}-\pi$ interactions between the alkyl moiety of the alcohols and aromatic rings of the cavitand play a major role in complex formation.

Besides the orientation of the $\mathrm{P}=\mathrm{O}$ groups, also the number and relative position of inwards directed $\mathrm{P}=\mathrm{O}$ oxygens strongly affect both the formation of the complexes and their stability. The more abundant formation and greater stability of ABii cavitands is not due to a greater number of hydrogen bonds but to the ability of the protonated cavitands to form a hydrogen bond network with alcohols, in which the cavitand operates as both hydrogen bond donor and hydrogen bond acceptor. The formation of a hydrogen bond network also affects the complexation behavior of the cavitands, as the cavitands capable of forming a network seem to prefer secondary and tertiary alcohols, whereas those able to form only single hydrogen bonds without any cooperation prefer primary alcohols in complexation. This difference is caused by the different location of the alcohol in these two types of complexes.

All investigated cavitands showed increased complex formation as the length of the alkyl chain of the alcohol increased. It was suggested that this might be due to the increased proton affinity of the longer chain alcohols, their decreased solvation, or the greater freedom of the long alkyl chain, which would allow the guest to experience a higher number of $\mathrm{CH}-\pi$ interactions with the cavitand. Since alcohol chain length appeared to have no effect on the gas-phase stability of the complexes, increased proton affinity can be ruled out. It is reasonable to assume, therefore, that increased complex formation with longer chain length is caused by the decreased solvation or the different setting of $\mathrm{CH}-\pi$ interactions between the alcohols and cavitand. 
Besides the properties of the bridges, also the properties of the resorcarene skeleton affected the complexation behavior of the cavitands. $\mathrm{CH}_{3}$ substituents at apical positions tended to complicate the formation of complexes but increased their stability. Presumably, $\mathrm{CH}_{3}$ substituents hinder both the formation of complexes and the release of the guest during dissociation because of steric reasons, without any actual interaction with the guest. $\mathrm{CH}_{3}$ substituents also increase the $\pi$-basic character of the cavity, making $\mathrm{CH}-\pi$ interactions more effective. This effect of the apical substituents has also been observed in mass sensors [16]. Whether the observed behavior is based on steric or electronic reasons is difficult to conclude on the basis of the present experiments.

Mass spectrometric results were in agreement with earlier results obtained by crystallography and mass sensor measurements. Studying the complexation of a neutral guest with a neutral host by mass spectrometry is not straightforward because of the requirement of charge. In this study, charge was provided by protonation of the host, which complicates the comparison of the results with the results of other methods. Nevertheless, mass spectrometric study produced valuable information about the receptor properties of cavitand hosts. Careful experimental setup and interpretation of the results is essential.

\section{Acknowledgments}

The authors gratefully acknowledge funding from the Academy of Finland, grant 200800, and MURST (Rome, Italy).

\section{References}

1. Moran, J. R.; Karbach, S.; Cram, D. J. Cavitands: Synthetic Molecular Vessels. J. Am. Chem. Soc. 1982, 104, 5826-5828.

2. Rudkevich, D. M.; Rebek, J., Jr. Deepening Cavitands. Eur. J. Org. Chem. 1999, 1991-2005.

3. Cram, D. J.; Cram, J. M. Container Molecules and Their Guests; RSC: Cambridge, 1994; p 85

4. Cram, D. J.; Karbach, S.; Kim, H.-E.; Knobler, C. B.; Maverick, E. F.; Ericson, J. L.; Helgeson, R. C. Host-Guest Complexation. 46. Cavitands as Open Molecular Vessels Form Solvates. J. Am. Chem. Soc. 1988, 110, 2229-2237.

5. Cram, D. J.; Stewart, K. D.; Goldberg, I.; Trueblood. K. N. Complementary Solutes Enter Nonpolar Preorganized Cavities in Lipophilic Noncomplementary Media. I. Am. Chem. Soc. 1985, 107, 2574-2575.

6. Tucker, J. A.; Knobler, C. B.; Trueblood, K. N.; Cram, D. J. Host-Guest Complexation. 49. Cavitands Containing Two Binding Cavities. J. Am. Chem. Soc. 1989, 111, 3688-3699.

7. Moran, J. R.; Ericson, J. L.; Dalcanale, E.; Bryant, J. A.; Knobler, C. B.; Cram, D. J. Vases and Kites as Cavitands. J. Am. Chem. Soc. 1991, 113, 5707-5714.

8. Cram, D. J.; Choi, H.-J.; Bryant, J. A.; Knobler, C. B. Solvophobic and Entropic Driving Forces for Forming Velcraplexes, Which are Four-Fold, Lock-Key Dimers in Organic Media. J. Am. Chem. Soc. 1992, 114, 7748-7765.

9. Lippmann, T.; Wilde, H.; Dalcanale, E.; Mavilla, L.; Mann, G.; Heyer, U.; Spera, S. Synthesis and Configurational Analysis of a Novel Class of Cavitands Containing Four Dioxaphosphocin Moieties. J. Org. Chem. 1995, 60, 235-242

10. Dalcanale, E.; Jacopozzi, P.; Ugozolli, F.; Mann, G. Synthesis and Configurational Analysis of Mixed-Bridged Phosphonate Cavitands. Supramol. Chem. 1998, 9, 305-316.

11. Pinalli, R.; Suman, M.; Dalcanale, E. Cavitands at Work: From Molecular Recognition to Supramolecular Sensors. Eur. J. Org. Chem. 2004, 451-462.

12. Nelli, P.; Dalcanale, E.; Faglia, G.; Sberveglieri, G.; Soncini, P. Cavitands as Selective Materials for QMB Sensors for Nitrobenzene and Other Aromatic Vapors. Sens. Actuators B 1993, 13/14, 302-304.

13. Hartmann, J.; Auge, J.; Lucklum, R.; Rösler, S.; Hauptmann, P.; Adler, B.; Dalcanale, E. Supramolecular Interactions on Mass Sensitive Sensors in Gas-Phases and Liquids. Sens. Actuators B 1996, 34, 305-311.

14. Hartmann, J.; Hauptmann, P.; Levi, S.; Dalcanale, E. Chemical Sensing with Cavitands: Influence of Cavity Shape and Dimensions on the Detection of Solvent Vapors. Sens. Actuators B 1996, 35/36, 154-157.

15. Ferrari, M.; Ferrari, V.; Marioli, D.; Taroni, A.; Suman, M.; Dalcanale, E. Cavitand-Coated PZT Resonant Piezo-Layer Sensors: Properties, Struc- ture, and Comparison with QCM Sensors at Different Temperatures under Exposure to Organic Vapors. Sens. Actuators B 2004, 103, 240-246.

16. Pinalli, R.; Nachtigall, F. F.; Ugozzoli, F.; Dalcanale, E. Supramolecular Sensors for the Detection of Alcohols. Angew. Chem. Int. Ed. 1999, 38, 2377-2380.

17. Suman, M.; Freddi, M.; Massera, C.; Ugozzoli, F.; Dalcanale, E. Rational Design of Cavitand Receptors for Mass Sensors. J. Am. Chem. Soc. 2003, $125,12068-12069$.

18. Suman, M.; Bouzouane, N.; Barbieri, E.; Ugozzoli, F.; Dalcanale, E. Cavitand-Based Supramolecular Sensors for the Detection of Acetates. J. Supramol. Chem. 2002, 2, 97-106.

19. Yamashita, M.; Fenn, J. B. Electrospray Ion Source. Another Variation on the Free-Jet Theme. J. Phys. Chem. 1984, 88, 4451-4459.

20. Fenn, J. B.; Mann, M.; Meng, K. C.; Wong, S. F.; Whitehouse, C. M. Electrospray Ionization for Mass Spectrometry of Large Biomolecules. Science 1989, 246, 64-70.

21. Cole, R. B., Ed. In Electrospray Ionization Mass Spectrometry; Wiley: New York, 1997.

22. Bruins, A. P. Mechanistic Aspects of Electrospray Ionization. J. Chromatogr. A 1998, 794, 345-357.

23. Schalley, C. A. Molecular Recognition and Supramolecular Chemistry in the Gas Phase. Mass Spectrom. Rev. 2001, 20, 253-309.

24. Dearden, D. V.; Liang, Y.; Nicoll, J. B.; Kellersberger, K. A. Study of Gas-Phase Molecular Recognition Using Fourier Transform Ion Cyclotron Resonance Mass Spectrometry. J. Mass Spectrom. 2001, 36, 989-997.

25. Brodbelt, J. S. Probing Molecular Recognition by Mass Spectrometry. Int. J. Mass Spectrom. 2000, 200, 57-69.

26. Schalley, C. A. Supramolecular Chemistry Goes Gas Phase: The Mass Spectrometric Examination of Noncovalent Interactions in Host-Guest Chemistry and Molecular Recognition. Int. J. Mass Spectrom. 2000, 194, $11-39$.

27. Daniel, J. M.; Friess, S. D.; Rajagopalan, S.; Wendt, S.; Zenobi, R. Quantitative Determination of Noncovalent Binding Interactions Using Soft Ionization Mass Spectrometry. Int. J. Mass Spectrom. 2002, 216, 1-27.

28. Vincenti, M.; Irico, A.; Dalcanale, E. 1998; Host-Guest Interactions in Mass Spectrometry. Karjalainen, E. J.; Hesso, A. E.; Jalonen, J. E.; Karjalainen, U. P., Eds.; In Advances in Mass Spectrometry; pp 129-150. Elsevier: Amsterdam,

29. Vincenti, M.; Dalcanale, E.; Soncini, P.; Guglielmetti, G. Host-Guest Complexation in the Gas Phase by Desorption Chemical Ionization Mass Spectrometry. J. Am. Chem. Soc. 1990, 112, 445-447.

30. Vincenti, M.; Dalcanale, E. Host-Guest Complexation in the Gas Phase. Investigation of the Mechanism of Interaction between Cavitands and Neutral Guest Molecules. I. Chem. Soc. Perkin Trans. 2. 1995, 1069-1076.

31. Nuutinen, J. M. J.; Irico, A.; Vincenti, M.; Dalcanale, E.; Pakarinen, J. M. H.; Vainiotalo, P. Gas-Phase Ion-Molecule Reactions between a Series of Protonated Diastereomeric Cavitands and Neutral Amines Studied by ESI-FTICRMS: Gas-Phase Inclusion Complex Formation. J. Am. Chem. Soc. 2000, 122, 10090-10100.

32. Irico, A.; Vincenti, M.; Dalcanale, E. Diastereoselective Formation of Host-Guest Complexes Between a Series of Phosphonate-Bridged Cavitands and Alkyl- and Arylammonium Ions Studied by Liquid Secondary-Ion Mass Spectrometry. Chem. Eur. J. 7203420012042

33. Vincenti, M.; Irico, A. Gas-Phase Interactions of Calixarene- and Resorcinarene-Cavitands with Molecular Guests Studied by Mass Spectrometry. Int. J. Mass Spectrom. 2002, 214, 23-36.

34. Woodget, B. W.; Cooper, D. Samples and Standards; Wiley: Chichester, 1987; pp 40-47

35. Hamilton, L. F.; Simpson, S. G.; Ellis, D. W. Calculations of Analytical Chemistry; McGraw-Hill: New York, 1960; pp 2-11

36. McGormick, D.; Roach, A. Measurements, Statistics, and Computation; Wiley: Chichester, 1987; pp 24-31

37. de Koning, L. J.; Nibbering, N. M. M.; van Orden, S. L.; Laukien, F. H. Mass Selection of Ions in a Fourier Transform Ion Cyclotron Resonance Trap Using Correlated Harmonic Excitation Fields (CHEF). Int. J. Mass Spectrom. Ion Processes 1997, 165/166, 209-219.

38. Hop, C. E. C. A.; McMahon, T. B.; Willett, G. D. Determination of Bond Dissociation Energies via Energy-Resolved Collision Induced Dissociation in a Fourier Transform Ion Cyclotron Resonance Spectrometer. Int. J. Mass Spectrom. Ion Processes 1990, 101, 191-208.

39. Sievers, H. L.; Grützmacher, H.-F.; Caravatti, P. The Geometrical Factor of Infinitely Long Cylindrical ICR Cells for Collision Energy-Resolved Mass Spectrometry: Appearance Energies of $\mathrm{EI}_{2}^{+}(\mathrm{E}=\mathrm{P}, \mathrm{As}, \mathrm{Sb}$, and $\mathrm{Bi})$ from Collision-Induced Dissociation of $\mathrm{EI}_{3}{ }^{+}$and $\left[\mathrm{EI}_{2} \cdot \text { ligand }\right]^{+} \mathrm{Com}-$ plexes. Int. J. Mass Spectrom. Ion Processes 1996, 157/158, 233-247.

40. Heeren, R. M. A.; Vekey, K. A Novel Method to Determine Collisional Energy Transfer Efficiency by Fourier Transform Ion Cyclotron Resonance Mass Spectrometry. Rabid Commun. Mass Spectrom. 1998, 12, 1175-1181.

43. Jacopozzi, P.; Dalcanale, E.; Spera, S.; Chrisstoffels, L. A. J.; Reinhoudt D. N.; Lippmann, T.; Mann, G. Synthesis and Configurational Analysis of Phosphonate Cavitands. J. Chem. Soc. Perkin Trans. 2 1998, 3, 671-677.

44. Kamlet, M. J.; Abboud, J.-L. M.; Abraham, M. H.; Taft, R. W. Linear Solvation Energy Relationships. 23. A Comprehensive Collection of the Solvatochromic Parameters, $\pi^{*}, \alpha$, and $\beta$, and Some Methods for Simplifying the Generalized Solvatochromic Equation. J. Org. Chem. 1983, 48, 2877-2887.

45. Gonçalves, R. M. C.; Simoes, A. M. N.; Albuquerque, L. M. P. C.; Roses, M.; Rafols, C.; Bosch, E. Kamlet-Taft Solvatochromic Parameters for Hydroxylic Solvents. J. Chem. Res. Synop. 1993, 214-215. 